\title{
On the drop-weight testing of alumina/aluminum laminated composites
}

\author{
MUSTAFA ÜBEYLI $\dot{I}^{1, *}$, R ORHAN YILDIRIM $^{2}$ and \\ BILGEHAN ÖGEL ${ }^{3}$
}

${ }^{1}$ TOBB Ekonomi ve Teknoloji Üniversitesi Mühendislik Fakültesi, Makine Mühendisliği, Ankara, Turkey

${ }^{2}$ ODTÜ, Makine Mühendisliği Bölümü, Ankara, Turkey

${ }^{3}$ ODTÜ, Metalurji ve Malzeme Mühendisliği Bölümü, Ankara, Turkey

e-mail: mubeyli@etu.edu.tr

MS received 17 December 2004; revised 4 March 2005

\begin{abstract}
Laminated composites with ceramic front layers and metallic or composite backing layers have gained attractiveness as lightweight armours, as they exhibit the same ballistic performance with lower areal densities as compared to steels. Drop-weight testing (DWT) has potential for evaluating the low velocity impact behaviour of materials. This testing gives significant ideas and information about failure mechanisms and behaviour of materials under low velocity impact. In this study, DWT of alumina/aluminum laminated composites was done in order to investigate the effects of lamination type, density with respect to area and mechanical property of backing material on the low velocity ballistic performance of these composites. The experimental results showed that the laminated composite with ceramic front layer and aged-aluminum alloy as backing layer was the most effective among different investigated specimens against low velocity impact loads.
\end{abstract}

Keywords. Laminated composite; impact; drop-weight testing.

\section{Introduction}

Selection and use of materials as armour in defence systems is of paramount importance, considering the system's overall benefit. In such systems, full protection against any threats should be maintained with armours of minimum weight to increase mobility of defence systems and save energy. Laminated composite materials have been defined as potential candidate lightweight materials for armour due to their distinct properties. Laminated composites have two main layers. The front layer is made up of ceramic material while the backing layer consists of metallic or composite plates. In this type of material, each layer has its own functions in resisting ballistic threats. The ceramic plate breaks up and erodes the projectile and increases the contact surface of the metallic plate by forming a hard cone and reducing the local pressure in the backup whereas the metallic or composite backup absorbs the kinetic

*For correspondence 
energy of the impactor and supports the ceramic particles. In laminated-composite armour research, alumina as a ceramic front layer and aluminum alloy as the backing layer have evoked wide interest owing to the fact that these materials are relatively cheap, light and easily available, as compared to other candidate materials. For ballistic testing of materials for armour, different types of test techniques have been used. Drop-weight testing (DWT) is a relatively simple method among these.

DWT was developed specifically for the determination of NDT (nil ductility temperature) on full thickness plates (Dieter 1988). It can also be by metal-forming operations since it is simple and economical in design. Recently, it has also been used as a ballistic test method to investigate the low velocity impact damage of materials since it has the potential to eliminate the time-consuming and rather expensive low-velocity real ballistic tests. Some researchers (Liu et al 1988; Chiu et al 1997; Sutherland \& Soares 1999; Hazizan \& Cantwell 2003; Shyr \& Pan 2003) used DWT to analyse impact response of materials. Hazizan \& Cantwell (2003) investigated the low velocity ballistic damage of aluminum honeycomb sandwich structures. In another study, Shyr \& Pan (2003) examined impact behaviour and damage characteristics in various reinforced fabric structures with different numbers of layers. They concluded that layer number was one of the important parameters for the energy-absorbing mechanism in composite laminates. Şimşir (2002) investigated the ballistic behaviour of Ck67 steel having different hardnesses using drop-weight tests. He found that the ballistic limit of steel plates changed in a linear relationship with hardness. Kalay (2003) examined the drop-weight testing of monolithic and layered AA-2024 plates. He also observed that ballistic limit increased with increased hardness and tensile strength of plates, and monolithic plates showed better ballistic performances than layered plates of equal thicknesses. A study on the impact test of woven-roving e-glass/polyester laminates was conducted by Sutherland \& Soares (1999). In another study, impact damage on cross-ply laminates made of glass-epoxy composites was investigated by Liu et al (1988). They found that delamination played a very important role in the characterizations of mechanical property degradation and thickness effects were much more significant than in-plane dimensional effects. Furthermore, Chiu et al (1997) studied the low velocity impact behaviour of pre-stressed composite laminates. They showed that the impact behaviour of composite laminates was highly related to both pretension and pre-compression. An extensive study of ballistic failure mechanisms of the alumina ceramic backed by semi-infinite steel or aluminum alloy was investigated by Sherman \& Brandon (1997) either by using DWT or real ballistic tests using 0.3 cal armour piercing projectiles. In this study, DWT of alumina/aluminum laminated composites of varying areal density with respect to area and lamination combinations was conducted to investigate their response to low velocity impact. In addition, macro- and micro-structural observations on tested samples were made. Finally, failure mechanisms during penetration and perforation by the impactor were investigated.

\section{Drop-weight testing setup}

A simple gravity drop-weight machine has been constructed in a previous study in the Mechanical Engineering Department of Middle East Technical University (Çolakoğlu 2002). The drop-weight test (DWT) was designed at first for metal-forming operations such as bar cropping sheet. However, in a previous study (Şimşir 2002), it was redesigned for low velocity ballistic characterization purposes. Figure 1 depicts a schematic view of the DWT setup. In order to use the drop-weight machine for ballistic purposes, six new pieces were designed and constructed. The modifications were as follows. 


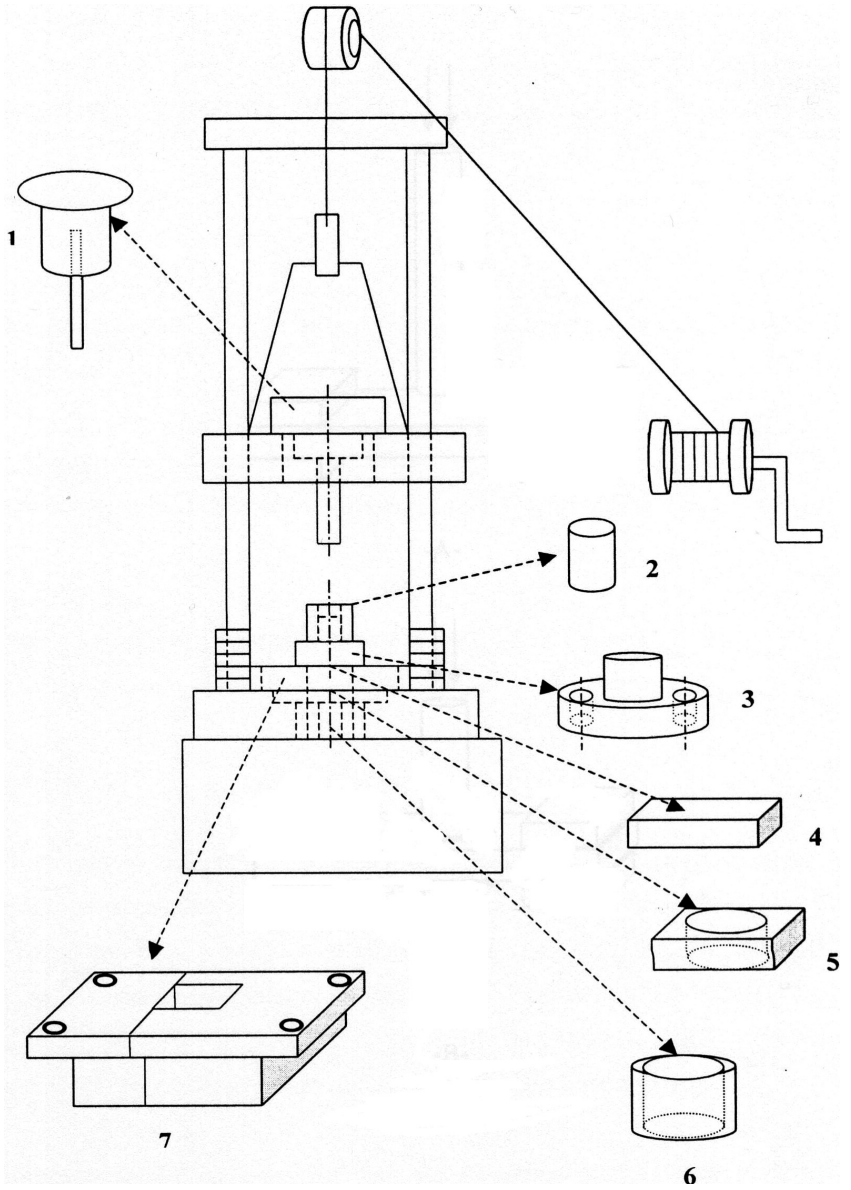

Figure 1. Schematic view of DWT setup.

(1) Hammer: An eight-kilogram steel part is used as the drop-weight hammer. A punch with a diameter of $8 \mathrm{~mm}$ is fixed at the bottom of the steel hammer, by means of which the impact on the specimen is achieved.

(2) Shock absorber: An aluminum pipe of diameter $50 \mathrm{~mm}$, height $55 \mathrm{~mm}$ and thickness $2 \mathrm{~mm}$ is used to absorb the excess energy of the falling weight after impact.

(3) Fixing plate: The purpose of the fixing plate is to hold the aluminum pipe and to fix the specimen. Also this part serves as a preserver for the guides in the case where the Al pipe gets deformed.

(4) Specimen: Specimens are placed in the cavity of the vice that is made of slightly larger dimensions compared to the specimens.

(5) Bottom fixing plate: For this study, a rectangular steel holder with dimensions $50 \times 50 \times$ $20 \mathrm{~mm}$ and with a hole $20 \mathrm{~mm}$ in diameter is used to fix the specimen. The $20-\mathrm{mm}$ diameter hole is drilled so that the punch can pass through the part after hitting the specimen.

(6) Holder: Beneath the holder, a cylindrical steel part is used as a back holder. A 20-mm hole is also drilled in to this cylindrical part, so the rod can pass through until stopped by the Al pipe. 
Table 1. Nominal chemical composition of CrMoV steel.

\begin{tabular}{|c|c|c|c|c|c|c|c|c|}
\hline$\%$ Element & $\%$ Total C & $\% \mathrm{Si}$ & $\% \mathrm{Mn}$ & $\% \mathrm{Cr}$ & $\% \mathrm{Mo}$ & $\% \mathrm{~V}$ & $\% \mathrm{P}$ & $\% \mathrm{~S}$ \\
\hline Minimum & $2 \cdot 30$ & 0.55 & $0 \cdot 30$ & $12 \cdot 50$ & $1 \cdot 10$ & 4.00 & 0.05 & $0 \cdot 05$ \\
\hline Maximum & & 0.65 & $0 \cdot 50$ & & & & & \\
\hline
\end{tabular}

(7) Vice: This part consists of two parts. The vice is fixed to the anvil by four bolts. It holds the other parts and the excess energy of the falling weight is transmitted to the anvil through the vice. Since the shape of the inner cavity of the part is similar to a closed box, all the broken pieces of the specimens are recoverable after the perforation.

Selection of suitable impactor materials and their properties is very important in dropweight tests. Among these properties, hardness of penetrator is very important, since low hardness penetrators (compared to the target plate) tend to deform rather than penetrate the target. In some cases, both penetration and partial deformation of penetrator occurs. Other important criteria for the penetrator are the compressive strength and the elastic modulus. Both of these should be high enough to prevent buckling failure. Furthermore, the toughness of the penetrator is also very important; the penetrator should not fail in a brittle manner during ballistic impact. CrMoV steel was chosen for use as a penetrator rod. This steel is a cold-worked tool steel with high hardness, compressive strength and elastic modulus. Its nominal chemical composition is given in table 1 . The $\mathrm{CrMoV}$ penetrator is heat-treated to $56 \mathrm{HRc}$. The penetrator rod is $8 \mathrm{~mm}$ in diameter and $11 \mathrm{~cm}$ in height.

\section{Experimental procedure}

\subsection{Aging and mechanical testing of AA-2024 plates}

AA-2024 plates were bought from the market in annealed conditions (T0). AA-2024 plates of $5 \times 5 \mathrm{~cm}$ size were solutionized at $490^{\circ} \mathrm{C}$ in a furnace for 1 hour to produce a single $\alpha$-phase. They were then quenched in a water-bath at $10^{\circ} \mathrm{C}$. After this, they were aged at $220^{\circ} \mathrm{C}$ for an hour in an oil-bath to obtain the intermediate S' phase for improved mechanical properties. Finally, they were quenched in water to complete the aging treatment. Tensile properties and hardness of $\mathrm{Al}-2024$ plates for $\mathrm{T} 0$ (as received) and T6 (after aging) conditions were measured. In addition, hardness values were obtained by the Brinell hardness test using a $2.5-\mathrm{mm}$ steel ball indenter under $613 \mathrm{~N}$ or $1839 \mathrm{~N}$ load, depending on the hardness level. Table 2 gives the mechanical properties of Al-2024 plates for $\mathrm{T} 0$ (as received) and $\mathrm{T} 6$ (after

Table 2. Mechanical properties of alloys Al-2024-T0 and A12024-T6.

\begin{tabular}{lccc}
\hline Alloy & $\begin{array}{c}\text { Hardness } \\
(\mathrm{HBN})\end{array}$ & $\begin{array}{c}\text { Yield strength } \\
(\mathrm{MPa})\end{array}$ & $\begin{array}{c}\text { UTS } \\
(\mathrm{MPa})\end{array}$ \\
\hline Al-2024-T0 & 52 & 80 & 194 \\
Al-2024-T6 & 150 & 390 & 500 \\
\hline
\end{tabular}


Table 3. Some important properties of alumina.

\begin{tabular}{ll}
\hline Purity & $99 \%$ \\
Density & $3 \cdot 8 \mathrm{~g} / \mathrm{cm}^{3}$ \\
Hardness & $9(\mathrm{Mohs}$ scale) \\
Compressive strength & $2 \cdot 1 \mathrm{GPa}$ \\
Flexural strength & $330 \mathrm{MPa}$ \\
\hline
\end{tabular}

aging) conditions. We can see clearly that aging has improved the mechanical properties of AA-2024 remarkably. This is directly due to precipitation-strengthening mechanisms caused by uniformly dispersed precipitates in the aluminum matrix. Surfaces of aluminum plates of thicknesses 2, 3 and $5 \mathrm{~mm}$ were prepared by using the FPL (Forest Products Laboratory) method (Cagle 1973) for good, effective bonding with alumina.

\subsection{Alumina}

Alumina tiles of dimensions of $5 \mathrm{~cm} \times 5 \mathrm{~cm}$ and thickness 4, 6, 8 and $10 \mathrm{~mm}$ were obtained from the market. Some properties for alumina are given in table 3 . As can be seen, alumina has high purity, high hardness and compressive strength values. The surfaces of the alumina plates were cleaned by the following procedure.

- Rubbing with $\mathrm{SiC}$ sandpaper (of size 100);

- degreasing with toluene;

- rinsing with clean tap water and through drying.

\subsection{Mechanical characterization of adhesives}

Epoxy-based adhesive was chosen for bonding laminates of composite specimens to be tested. Tensile strength and lap-shear strength are the key properties of substances use as adhesives. Another important step before adhesive application is preparation of the surface of samples that have to be bonded. Surfaces of test specimens were treated by the standard FPL method (Cagle 1973). Tensile and lap-shear tests for adhesive characterization were done according to ASTM D 897 (ASTM 1993a) and ASTM D 1002-72 (ASTM 1993b) respectively. According to test results, tensile and lap shear strengths of epoxy were 25 and $17 \mathrm{MPa}$ respectively.

\subsection{DWT specimens}

Specimen types of dimensions $5 \mathrm{~cm} \times 5 \mathrm{~cm}$ were prepared by bonding surface-treated alumina and aluminum alloy plates for DWT (see table 4). Specimens were tested to study the effect of increasing alumina thickness and the mechanical properties of backing plate and lamination type on the ballistic performance of laminated composite systems. In order to examine these parameters, 16 different specimen types were considered. For each specimen type, 10 samples were prepared for drop-weight testing. Four different constant areal density values $(\sim 28,36$, 44 and $52 \mathrm{~kg} / \mathrm{m}^{2}$ ) were chosen as references for comparison.

$$
\text { Areal density }=t_{1} \cdot d_{1}+t_{2} \cdot d_{2}
$$


Table 4. Specimens prepared to be tested by DWT.

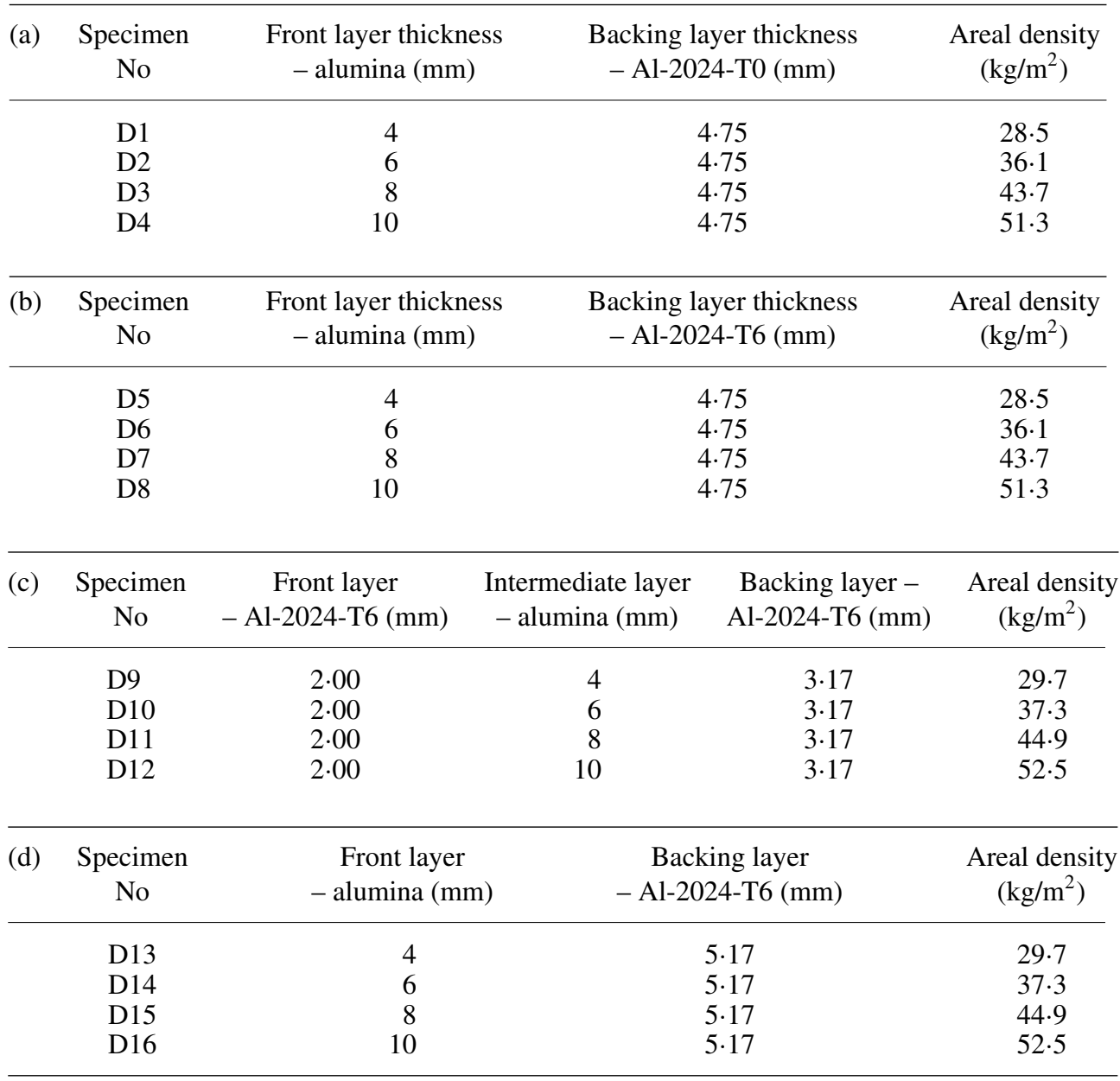

where $t_{1}$ and $t_{2}$ are thicknesses of the ceramic and aluminum layers and $d_{1}$ and $d_{2}$ represent density of the ceramic and aluminum layers respectively. The first eight specimen types had front alumina layers of different thicknesses and backing AA-2024 layers of constant thickness. In specimens 1-4, AA-2024-T0 backing plates were used, whereas AA-2024T6 plates were selected for specimens 5-8. In specimens 9-12, alumina was used as an intermediate layer for comparison with specimens 13-16 with alumina front layers.

The drop-weight test was used to obtain the 'ballistic limit' of prepared laminated composite specimens. Ballistic limit velocity is the minimum striking velocity at which perforation occurs for a projectile-armour system. In other words, it is the minimum velocity that can make a hole through armour, but does not necessarily cause any fragments to be displaced from the rear plate. The bisection method was used to determine the ballistic limit of the specimens examined in this study. This method involves punching the target plate from the average of the distances from which perforation does and does not occur. The procedure was repeated until the ballistic limit is determined. This procedure was used in order to reduce 
the number of experiments, rather than punching in gradually increasing or decreasing steps to determine the ballistic limit. Five samples were tested at the same velocity and height. If more than 50\% (i.e. at least 3 samples) behaved similarly as in the first stage, the value was taken as the ballistic limit. A digital camera capable of taking 30 frames per second was used to measure the impact velocity of the hammer, and to construct the height versus velocity graph. A series of photographs of the eight-kilogram hammer falling from different heights were transmitted to an image analyser program for analysis.

\section{Experimental results}

Figure 2 shows the ballistic limits found by DWT for specimens D1-D4 and D5-D8 using Al-2024-T0 and Al-2024-T6 as backing plates, respectively. Ballistic limit increases with increasing thickness of front alumina layer as expected. We can see that for all ceramic thicknesses, specimens D5, D6, D7 and D8 have higher ballistic limits than specimens D1, D2, D3 and D4 respectively. Differences in the ballistic limits due to the type of the backing plate in these models become smaller when ceramic thickness increases. Figure 3 illustrates

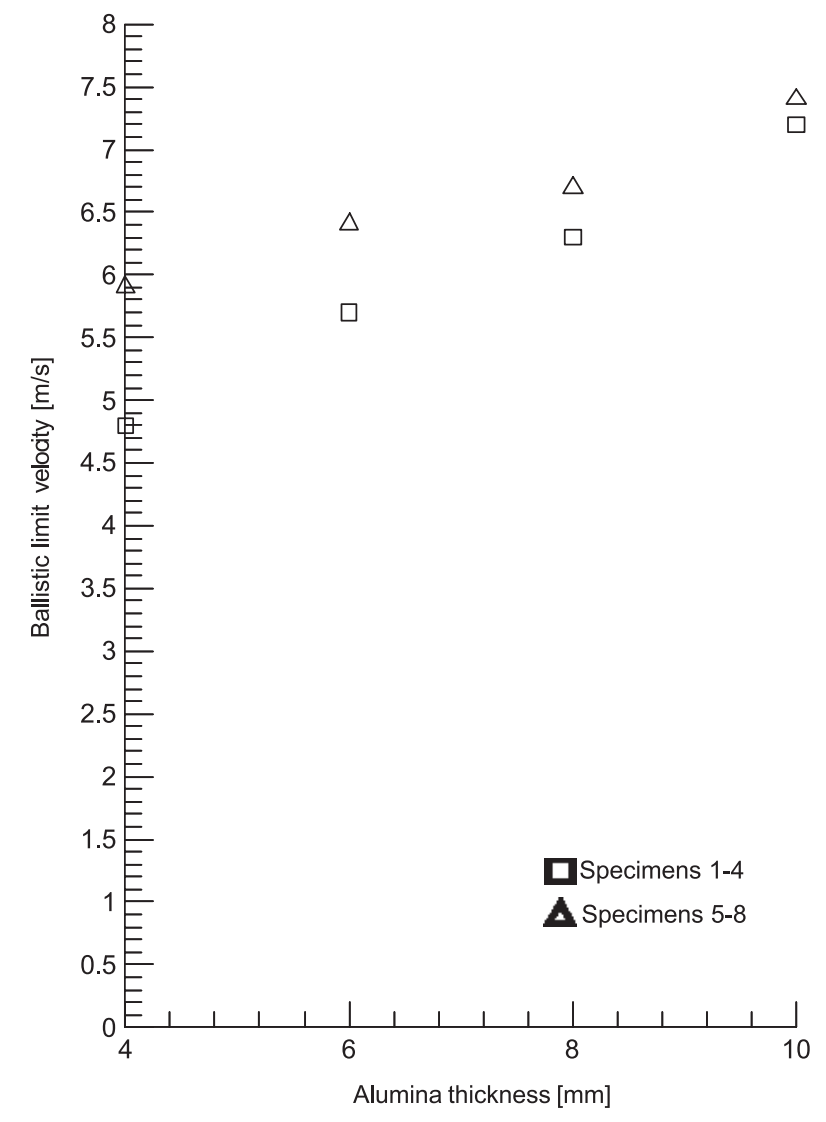

Figure 2. Ballistic limit velocity with respect to alumina thickness for specimens $1-8$. 


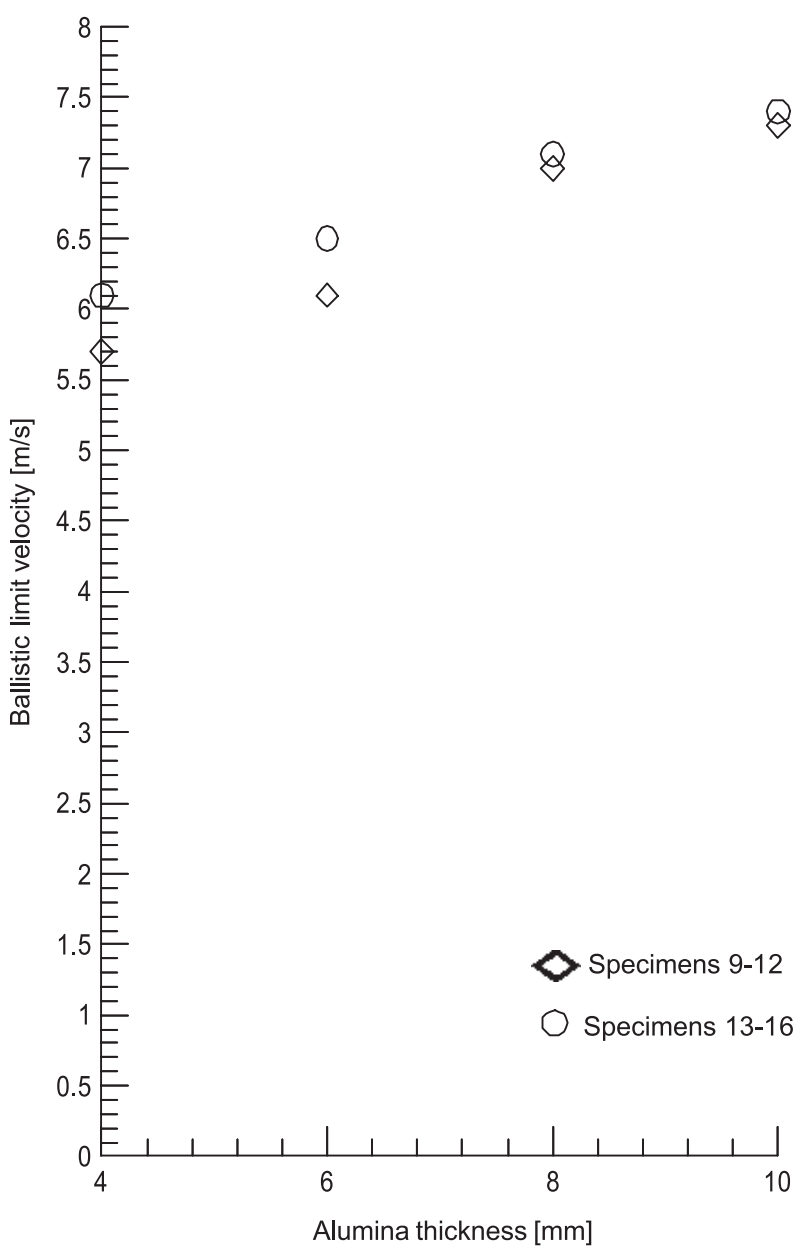

Figure 3. Ballistic limit velocity versus alumina thickness for specimens 9-16.

the ballistic limits of the specimens D9-D12 and D13-D16 with respect to alumina thickness. We can see from this figure that specimens D13 and D14 show higher impact resistance than specimens D9 and D10 respectively. However, the ballistic limits of D15 and D16 are very close to those of D11 and D12 respectively. This implies that using alumina as front layer in the specimens is more effective in enhancing ballistic performance. Either macroscopic or microscopic examination of the tested specimens gives valuable information about failure mechanisms from the penetration of projectiles to the perforation of specimens under impact loading.

\subsection{Macroscopic examination of tested specimens}

Figure 4 shows the front layer of the specimen D1 where the penetrator first hit. As can be observed, six main radial cracks and a hole with almost the same diameter as the penetrator have been formed. Figure 5 depicts the rear view of the front layer of the same specimen. Upon impact, the ceramic and aluminum layers have separated for all tested specimen types. Cone structure at an angle of around $60^{\circ}$ with respect to the impact axis is formed after impact 


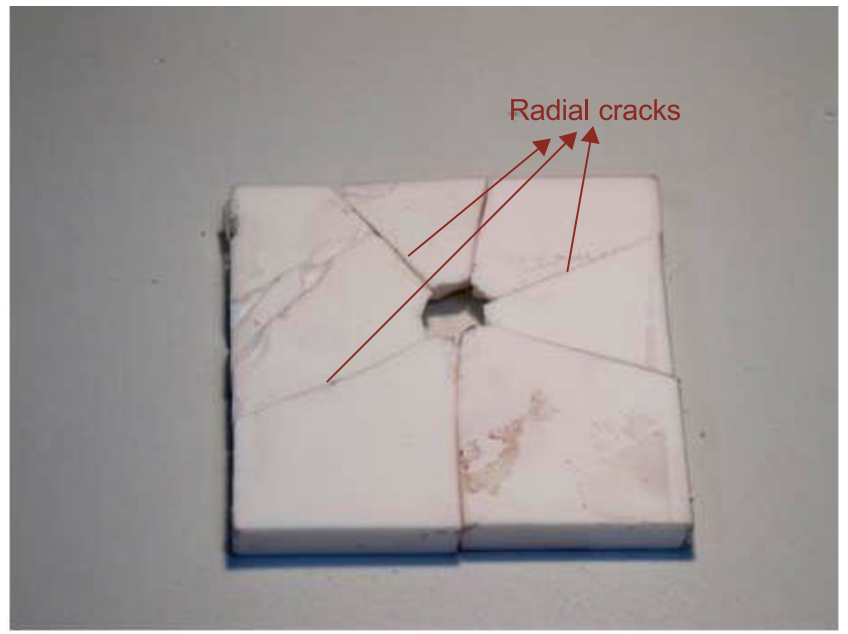

Figure 4. Front view of the specimen D1 after DWT.

as is seen clearly. Cone formation is observed in all specimens after DWT. The front and backing layers of the specimen D1 are shown in figure 6. On impact, the part of the aluminum plate where the highest pressure has been exerted by the penetrator, pulverized particle traces of ceramic material are seen. Specimen D3 subjected to DWT is seen in figure 7. While the alumina front layer is fractured into several main particles under impact, its cone part is completely crushed and pulverized along with penetration of the projectile. On the other hand, plugging type of deformation has occurred in the aluminum backing plate.

Figure 8 shows specimen D10 after impact by the hammer released at a height of $2 \mathrm{~m}$. The projectile has perforated the top aluminum layer easily shown at right side of this figure by forming a plug of almost the same diameter. The intermediate ceramic layer is fractured into several large particles while the ceramic cone centred at the impact axis is pulverized. On the bottom layer, the initial step of plug formation is observed.

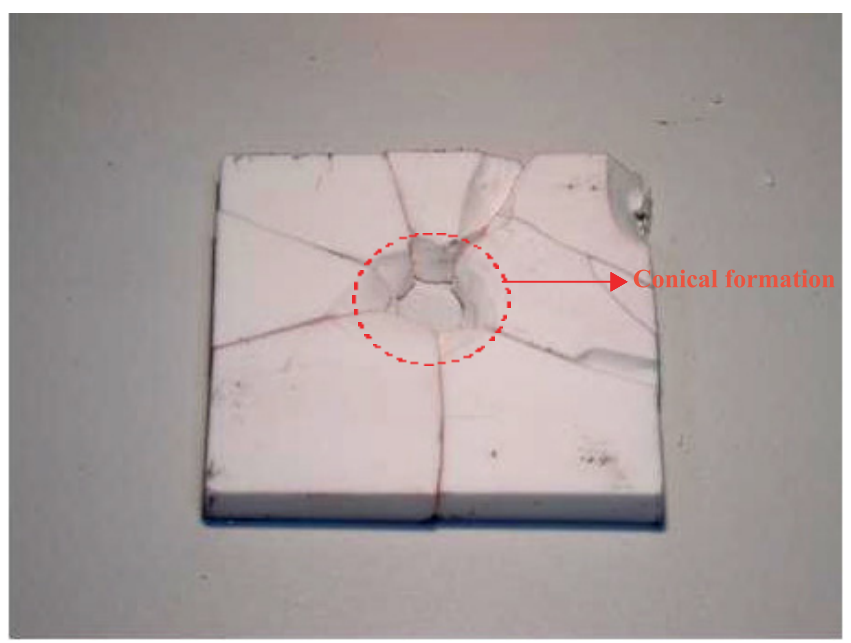

Figure 5. Rear view of the front layer of the specimen D1 after DWT. 


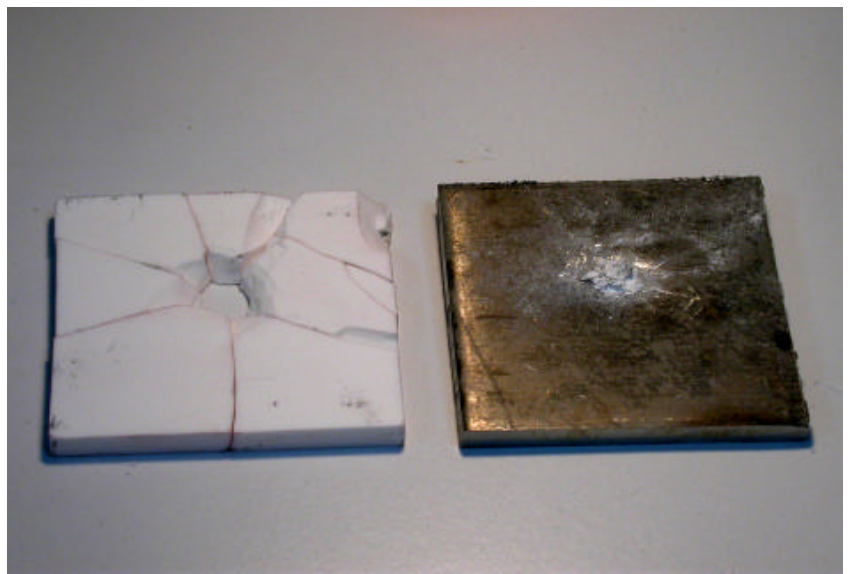

Figure 6. Front and backing layers of the drop-weight tested specimen D1.

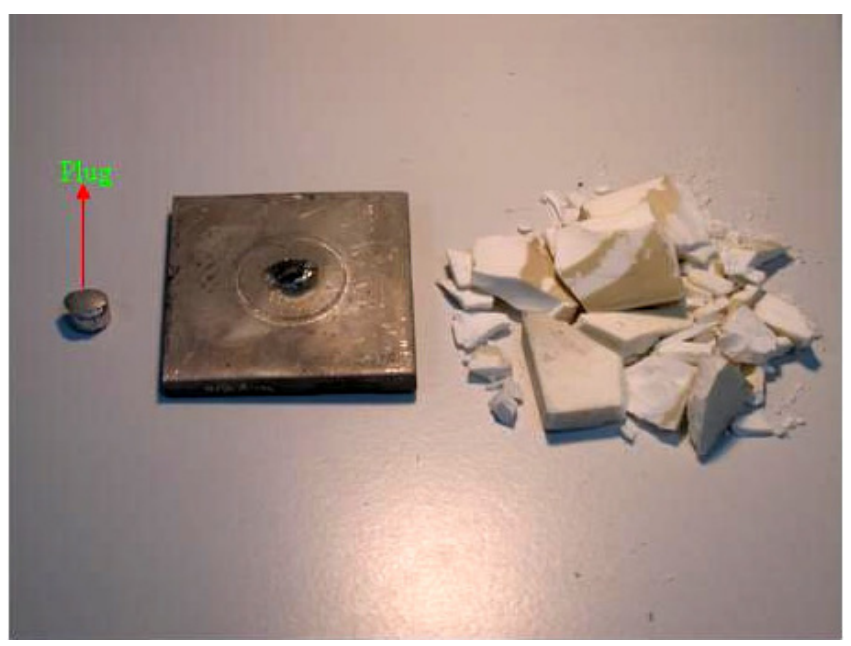

Figure 7. Sample D3 after DWT.

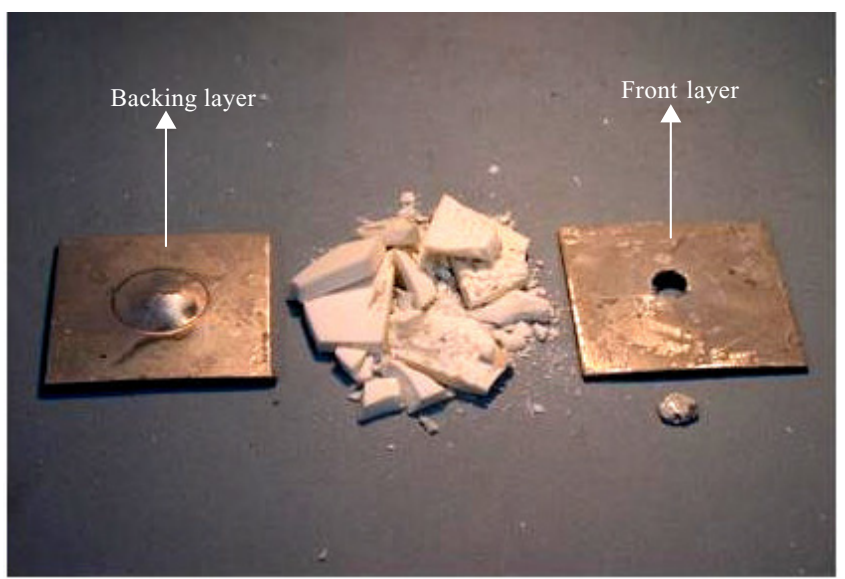

Figure 8. View of sample D10 after an impact of hammer released at a height of $2 \mathrm{~m}$. 


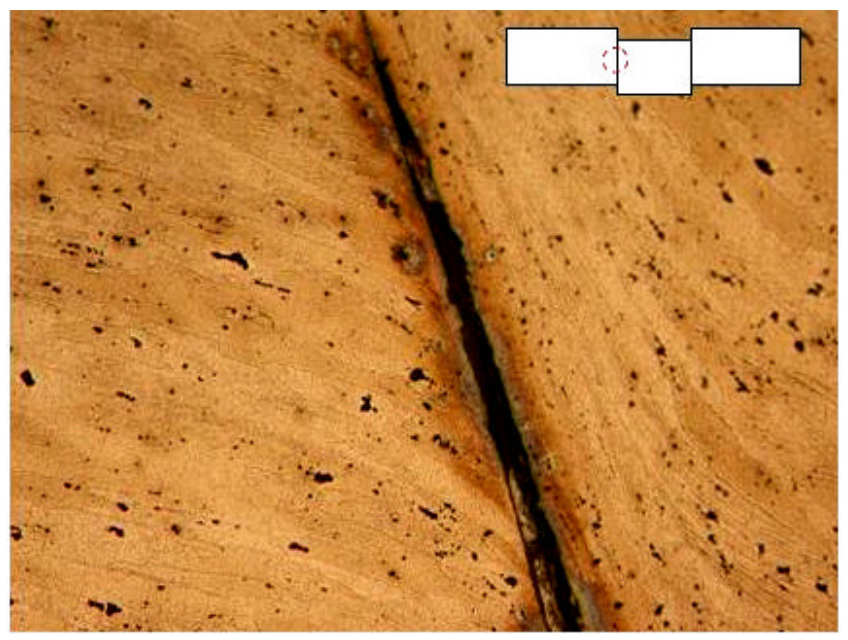

Figure 9. Formation of plug in AA-2024-T6 plate (X200).

\subsection{Microscopic examination of tested specimens}

Failure mechanisms in terminal ballistic studies are strongly related to the microstructure of the materials. In order to examine failure mechanisms in a comprehensive way, microscopic inspection of the specimens is needed. In this study, representative samples were selected and inspected by using optical microscopy to understand these mechanisms. As mentioned above, plugging was the principle type of deformation for aluminum plates, whereas cone formation was the main failure mechanism in alumina ceramic.

Plug type deformation taking place in metals on using blunt projectiles was the main mechanism of failure seen tested specimens. Figure 9 depicts the formation of plug in an aluminum plate. We can observe that under the high compressive pressure of the penetrator, shear bands occur intensely at the edges of the projectile. After localization of shear bands, microvoids form along the main shear path, where coalescence of these voids cause crack formation during penetration. As can be seen from figure 9, for the left-hand portion of the specimen, the direction of the shear bands of the plug is upward while that of the plate is downward. Similarly, figure 10 illustrates the right-hand portion the penetrated specimen on a micro scale. Intense shear localization has also cause the cracks formed at the edges of the plug and plate material.

\subsection{Failure mechanisms}

Failure mechanisms should be clarified to understand the ballistic behaviour of materials or systems. In drop-weight testing four damage mechanisms can be considered as follows.

(1) Tensile radial crack formation;

(2) cone formation in the ceramic layer;

(3) Crushing and pulverizing of cone structure;

(4) Plug formation in the aluminum backing layer.

4.3a Tensile radial crack formation: The damage occurring in the ceramic is in a wider range, due to the brittle nature of the material, whereas the damage on the metallic plates is 


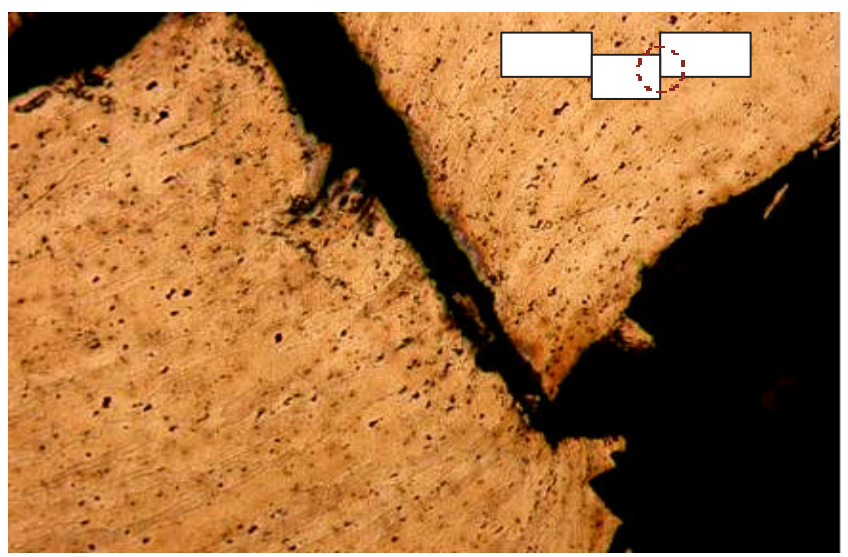

Figure 10. Separated plug from AA-2024-T6 plate (X200).

focused on the impact axis. After the impactor strikes the alumina layer, tensile radial cracks occur on the layer. After impact, these cracks originate from the rear face of the ceramic tile and travel back to the projectile. These cracks are caused by the reflected tensile waves of the compressive waves at the ceramic-adhesive interface. The impacted ceramic tile is completely fragmented in a very short time (a few microseconds) after impact (Sherman \& Brandon 1997). The coalescence of the cracks causes general fragmentation of the ceramic.

4.3b Cone formation: Cone crack formation is a slow mechanism compared to tensile radial cracks (Sherman \& Brandon 1997). Cone formation in ceramic tiles upon impact is the key situation to analyse ballistic performance of the laminated composites as stated before. Conical structures form in ceramic tiles even at very low velocities $(<5 \mathrm{~m} / \mathrm{s})$ during DWT. A fractured ceramic cone develops at the impact surface. Conical structure transferring the impactor energy to a much greater area at the aluminum layer is observed at the back of the alumina layers in all the samples.

4.3c Crushing and pulverizing of the cone structure: After impact ceramic fragmentation takes place during penetration. After fragmentation, the projectile penetrates a cone of comminuted, pulverized and fragmented ceramic. Small volume of comminuted ceramic with respect to the target tile is formed at the projectile-ceramic interface, where the highest pressure is exerted. Further penetration of the projectile through the cone ceramic depends on whether it can push the pulverized ceramic material aside.

4.3d Plugging formation in the aluminum backing layer: Highest stress concentration by the impactor on the impact axis causes shear forces at the periphery of the impactor circle. These shear forces then cause crack formation at the aluminum backing layer. The propagation and coalescence of these cracks causes plug formation. If the compressive stress loaded by the impactor is greater than the yield strength of the aluminum, then plastic deformation and plug formation start and if it is greater than the ultimate tensile strength of aluminum the plug separates from the aluminum layer. Impactor nose geometry selected in this study is the blunt and cylindrical type. Therefore, the deformation type at the aluminum layer is plug formation. 


\section{Discussion}

Improving the mechanical properties of the aluminum plate increases the ballistic resistance of composites. AA-2024-T0 alloy has poor mechanical properties with respect to AA-2024-T6. Therefore, the impactor can more easily penetrate and perforate samples of AA-2024-T0 than of AA-2024-T6.

Lamination type also affects the ballistic behaviour of composite specimens. Using ceramic as an intermediate layer is not an effective method of enhancing the ballistic resistance of a system. In this study, relatively thin aluminum layers were used as front layers and backing layers to keep the areal density constant in comparison to other samples using ceramic front layers. The impactor could easily penetrate the top aluminum layer. Ceramic cone then formed at the intermediate layers. Finally, the bottom aluminum layers with reduced thicknesses were also more easily penetrated and perforated by the impactor.

\section{Conclusions}

The main conclusions derived from this study are as follows:

- The lamination type, areal density and mechanical properties of aluminum plates affects low velocity ballistic performance significantly.

- Ballistic limit increases with increased areal density of the composites.

- In DWT, using front ceramic layers and aged-aluminum alloy (AA2024-T6) backing layers. appears to be the best protection against impact loads generated in the velocity range of $4-9 \mathrm{~m} / \mathrm{s}$.

This work was supported by the Research Fund of the Middle East Technical University, and State Planning Organization of Turkey.

\section{References}

ASTM 1993a ASTM Standards, Designation D 897-78 (reapproved 1983). Standard test method for tensile properties of adhesive bonds

ASTM 1993b ASTM Standards, Designation D 1002-72-78 (reapproved 1983). Standard test method for strength properties of adhesives in shear by tension loading (metal-to-metal)

Cagle C V 1973 Handbook of adhesive bonding (New York: McGraw-Hill)

Chiu S-T, Liou Y-Y, Chang Y-C, Ong C-L 1997 Low velocity impact behaviour of prestressed composite laminates. Mater. Chem. Phys. 47: 268-272

Çolakoğlu A 2002 Design and construction of a gravity drop hammer, MSc thesis, Mechanical Engineering Department, Middle East Technical University, Ankara, Turkey

Dieter G E 1988 Mechanical metallurgy (SI metric edition) (New York: McGraw-Hill)

Hazizan A Md, Cantwell W J 2003 The low velocity impact response of an aluminum honeycomb sandwich structure. Composites B34: 679-687

Kalay Y E 2003 Low velocity impact characterization of monolithic and laminated AA-2024 plates by drop-weight test. MSc thesis, Metallurgical and Material Engineering Department, Middle East Technical University, Ankara, Turkey 
Liu D, Raju B B, Dang X, 1998 Size effects on impact response of composites laminates Int. J. Impact Eng. 21: 837-854

Sherman D, Brandon D G 1997 The ballistic failure mechanisms and sequence in semi-infinite supported alumina tiles. J. Mater. Res. 12: 1135-1343

Shyr T-W, Pan Y-H 2003 Impact response and damage characteristics of composite laminates. Composite Struct. 62: 193-203

Sutherland L S, Soares C G 1999 Impact tests on woven-roving E-glass/polyester laminates. Composites Sci. Technol. 59: 1553-1567

Şimşir C 2002 Low velocity ballistic characterization of steel armour plates by drop-weight test. MSc thesis, Metallurgical and Material Engineering Department, Middle East Technical University, Ankara, Turkey 